\title{
IDENTIFICACIÓN DE VARIEDADES DEL PROGRAMA MEXICANO DE PAPA POR LOS PATRONES ELECTROFORETICOS DE PROTEÍNAS SOLUBLES
}

\author{
Humberto López *; Guillermo Carrillo **
}

\begin{abstract}
RESUMEN
Variedades de Solanum tuberosum L. fueron identificadas mediante el análisis electroforético de proteínas solubles del tubérculo. Se utilizaron geles delgados de dodecil sulfato de sodio-acrilamida en su modalidad horizontal. Se estudiaron siete genotipos, los cuales se agruparon en tres grupos por sus características fenotípicas y agronómicas muy similares. Con los patrones de proteínas obtenidos se pudo identificar a cada variedad con excepción de Alpha y AMR-69-1 que mostraron el mismo patrón. La técnica empleada permite analizar simultáneamente 24 muestras por gel, empleando sólo 60 minutos para la separación de las proteínas. Además los geles se hacen en moldes sin utilizar la cámara de electroforesis, lo cual permite preparar los geles y efectuar la separación electroforética de las proteínas simultáneamente. El método es, por tanto, recomendable para el análisis rutinario de proteínas e isoenzimas.
\end{abstract}

Palabras Claves Adicionales: $\quad$ Solanum tuberosum, gel, isoenzimas.

\section{SUMMARY \\ IDENTIFICATION OF MEXICAN POTATO (PROGRAM) CULTIVARS BY ELECTROPHORETIC PATTERNS OF SOLUBLE PROTEINS}

For identifying varieties of Solanum tuberosum a method consisting on thinlayer horizontal SDS polyacrylamide electrophoresis for the separation of

Aceptado para publicación: Mayo 16, 1991

\footnotetext{
* $\quad$ Programa Mexicano de Papa. Instituto Nacional de Investigaciones Forestales y Agropecuarias (INIFAP). PRECODEPA. C.P. 52140, Metepec, México.

** Centro de Genética, Colegio de Postgraduados, Montecillos, México. C.P.56230, México.
} 
proteins present in the tuber was evaluated. Seven genotypes which constituted three groups of cultivars of potatoes with similar phenotypic and agronomic characteristics were studied. By their protein patterns, it was possible to identify five out 'of the seven cultivars since Alpha and AMR69-1 displayed the same protein pattern. Using this procedure it is possible to analyse 24 samples under identical conditions using a single gel, and the proteins are subjected to electrophoresis only 60 minutes. This time-saving method has proved to be useful for routine analysis of potato tuber proteins.

Additional Index Words:

Solanum tuberosum, gel, izoenzymes.

La identificación de variedades de plantas de utilidad comercial es importante en el comercio internacional, manejo y procesamiento del producto agrícola, y en el mejoramiento genético. En el pasado, la identificación de las variedades se basaba solamente en las características fenotípicas de las plantas de fácil apreciación pero en la actualidad, se usan también los patrones electroforéticos de proteínas y enzimas $(1,5,12)$.

Cultivares de papa de Europa y los EEUU se han logrado identificar electroforéticamente y sus patrones difieren en el número, posición e intensidad de pigmentación de las bandas. También, este tipo de análisis contribuyó para determinar que las proteínas y enzimas de papa estaban controladas genéticamente $(5,6,12)$.

En Latinoamérica, ésta es la primera vez que una colección de papa cultivada es caracterizada mediante los patrones electroforéticos de proteínas por un Programa Nacional; sin embargo, muchas colecciones de papa de varios países latinoamericanos han sido caracterizadas electroforéticamente en el Centro Internacional de la Papa (5). Recientemente se están aplicando técnicas de análisis de polimorfismo de los fragmentos de restricción $(7,8,11)$ de ácido desoxirribonucleico (ADN) para determinar cambios genotípicos y por consiguiente asegurar la fidelidad de los materiales conservados en especial en los bancos de germoplasma.

En el presente trabajo se reportan los patrones de bandas de proteínas solubles del tubérculo de algunos cultivares mexicanos de papa utilizando como base el método de Gorg y colaboradores $(3,4)$. 


\section{MATERIALES Y MÉTODOS}

Tubérculos de S. tuberosum: Alpha, AMR-69-1, Juanita, Murca, Rosita y Sangema se obtuvieron del Banco de Germoplasma del Programa Mexicano de Papa del Instituto Nacional de Investigaciones Forestales y Agropecuarias, Metepec, Mex., México. De tubérculos de la misma edad fisiológica y estado de conservación se tomaron muestras de $500 \mathrm{mg}$ aproximadamente (peso fresco), se homogenizaron en un mortero helado, utilizando $1 \mathrm{~mL}$ de amortiguador de fosfato de potasio $0.01 \mathrm{M}$, pH 7.1 que contenía dodecil sulfato de sodio (SDS), $0.01 \%$ p/v. La preparación se centrifugó a 15,300 x g a $5^{\circ} \mathrm{C}$ durante 15 minutos y después se dializó el extracto contra dos cambios del mismo amortiguador de fosfatos durante 12 horas a $4^{\circ} \mathrm{C}$. La cantidad de proteína se determinó mediante el método de Lowry $\underline{\text { t }} \underline{\text { al }}(9)$.

La separación electroforética de las proteínas se llevó a cabo el mismo día en que se concluyó el proceso de obtención de los extractos, se utilizó una cámara para electroforesis horizontal LKB modelo 2117 suministrándose la corriente con una fuente de poder LKB modelo 2103. Los geles de 245 x 115 y $1 \mathrm{~mm}$ de espesor, se prepararon siguiendo en forma parcial las indicaciones de Gorg $\underline{e t} \underline{a l}$. $(3,4)$, los cuales contenían acrilamida, $8.5 \% \mathrm{p} / \mathrm{v}$; SDS, $0.1 \% \mathrm{p} / \mathrm{v}$ y amortiguador de fosfato de potasio $0.1 \mathrm{M} \mathrm{pH}$ 7.1; este mismo amortiguador fue utilizado en la cámara. Mediante una pre-electroforesis de 15 minutos se ajustaron condiciones de $200 \mathrm{~V}, 200 \mathrm{~mA}$ y $34.4 \mathrm{~W}$ máximas y temperatura de $15^{\circ} \mathrm{C}$. En las cubetas se colocaron $8 \mu \mathrm{l}$ de extracto (16 a $18 \mu \mathrm{g}$ de proteína), para nuevamente reestablecer las mismas condiciones y realizar la separación 'electroforética de las proteínas durante 60 minutos. Al término de este tiempo los geles se revelaron por otros 60 minutos con la solución de azul de comassie: después del proceso de desteñido se hizo el análisis de los patrones de proteína.

\section{RESULTADOS Y DISCUSIÓN}

Los cultivares estudiados fueron catalogados en tres grupos de acuerdo a sus características fenotípicas similares. Grupo 1: Juanita y Murca, Grupo 2: Rosita, Sangema y CGN-69-1 y Grupo 3: Alpha y AMR-69-1. Los patrones electroforéticos de proteína de cada uno de ellos se puede apreciar en la Figura 1. Con este sistema de análisis fue posible caracterizar a variedades de papa en estudio ayudando a definir su 
mismo grupo.

Esta técnica de separación de proteínas permite analizar simultáneamente 24 muestras por gel, en sólo 60 minutos, de tiempo de separación. La preparación de los geles se hace en moldes sin utilizar la cámara de electroforesis. Esto último permite preparar uno ó más geles y efectuar la separación electroforética de las proteínas simultáneamente. El empleo

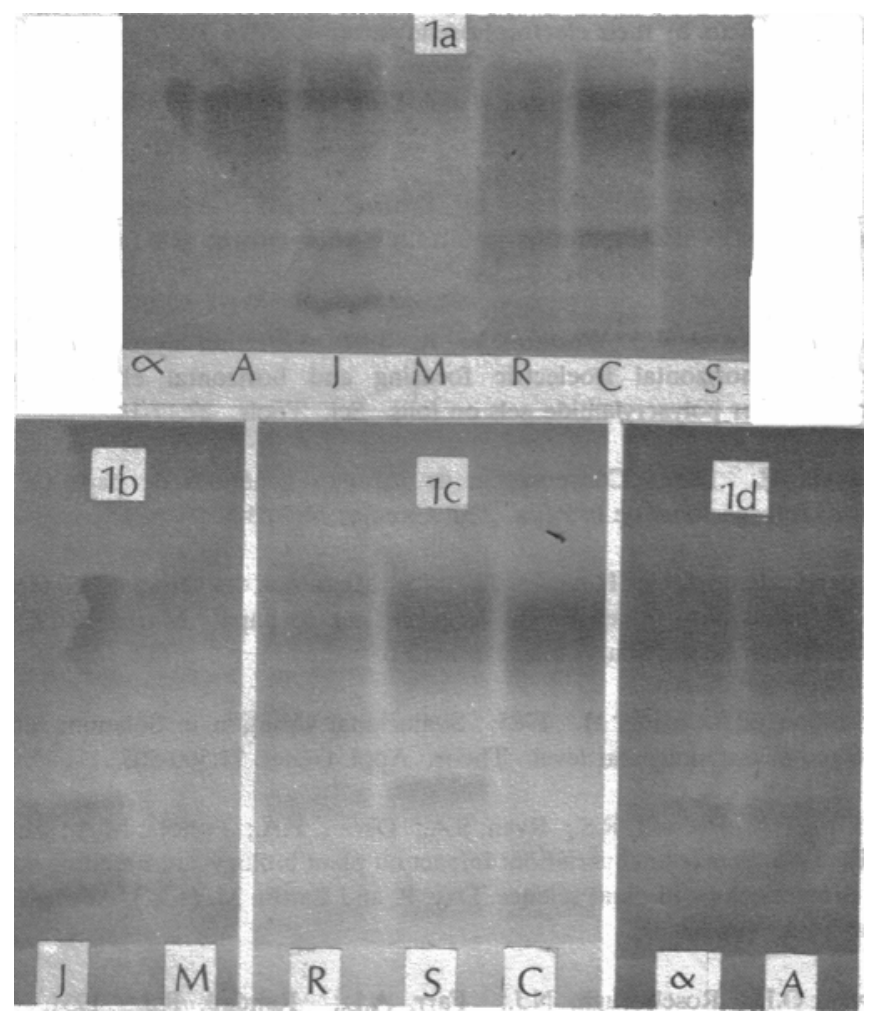

Figura 1. Patrones electroforéticos de las proteínas solubles de papa sobre el gel de poliacrilamida - SDS.

1a: Aspecto general de los 7 genotipos

1b: Genotipos: J: Juanita y M: Murca

1c: Genotipos: R: Rosita, S: Sangema y C: CGN-69-1

1d: Genotipos: $\alpha$ : Alpha y A: AMR-69-1 
sistemático de patrones electroforéticos de proteínas e isoenzimas permiten también determinar (con relativa precisión) el grado de variación de la expresión genética que pudiera manifestarse dentro de cada genotipo (13). Permite igualmente determinar la naturaleza órgano-específica de las proteínas relacionadas con la patogénesis $(2,10)$.

\section{REFERENCIAS BIBLIOGRÁFICAS}

1. $\quad$ Adriaanse A.; Klop, W.; Robbers, J.E. 1969. Characterization of Phaseolus vulgaris cultivare by their electrophoretic patterns. J.Sci. Fd. Agric. 20:647-650.

2. Bowles, D.J. 1990. Defense-Related Proteins in Higher Plats. Ann. Rev. Biochem. 59:873-907.

3. Gorg, A.; Postel, W.; Weser, J.; Schiwara, H.W.: Boensken, W.H. 1985. Horizontal SDS electrophoresis in ultrathin poregradient gels for the analysis of urinary proteins. Sci. Tools. 32:5-9.

4. Gorg, A.; Postel, W.; Westermeier, R. 1980. Ultrathin-layer protein mapping combining horizontal isoelectric focusing and horizontal electrophoresis in ultrathin-layer polyacrylamide gels on foils. Sci. Tools. 27:17-18.

5. Huamán, Z. 1986. Conservación de recursos genéticos de papa en el CIP. Centro Internacional de la Papa. CIP Circular 14(2):3-5.

6. Krogerrecklenfort, E.; Huamán, Z. 1985. Memorias del Curso sobre técnicas de electroforesis para la separación de proteínas de papa. Marzo 19-29. Centro Internacional de la Papa. Lima, Perú. 12 p.

7. Ladsmann, J.; Uhring, H. 1985. Somaclonal variation in Solanum tuberosum detected at the molecular level. Theor. Appl. Genet. 71:500-505.

8. $\quad$ Larking, P.J.; Brettell, R.S.; Ryan, SA.; Dsvies, P.A.; Pollota, M.A.; Scowcroft, W.R. 1985. Somaclonal variation: Impact on plant biology and breeding strategies. In: Biotechnology in plant science. Day, P. and Zaitlin M. (eds.), Academic Press, New York. pp. 83-100.

9. Lowry, O.H.; Rosebrough, N.J.; Farr, A.L.; Randall, R.J. 1951. Protein measurement with the Folin phenol reagent. J.Biol. Chem. 193: 265-275.

10. Ohshima, M.; Itoh, H.; Matsuoka, M.; Murakami, T.; Ohashi, Y. 1990. Analysis of stress-induced or salicylic acid-induced expression of the pathogenesis-related la protein gene in transgenic tobáceo. The Plant Cell. 2: 95-106.

11. Stegemann, H.; Franckesen, H.; Macko, V. 1973. Potato Proteins: Genetic and physiological changes evaluated by one and two dimensional PAA-geltechniques. N. Naturforsch 28: 722-822. 
12. Stegmann, H. 1979. SDS-PAGE, Merits and limits. In: Electrokinetic Separation Methods. Righetti, P.G. Van Oss, CJ. and Vanderhoffeds, J.W. (eds.), Elsevier North Holland, Amsterdam. pp. 313-336.

13. Steward, F.C. 1970. Cloning cells and controlling the composition of crops. Progress 54:44-51. 